\title{
El coleccionismo decimonónico y el Museo Nacional de San Carlos
}

L

A CONMEMoración de los primeros 40 años de vida del Museo Nacional de San Carlos (1968-2008) representa una excelente oportunidad para abordar, así sea someramente, dos fenómenos culturales disociados en la realidad mexicana: el coleccionismo de arte y la donación a museos.

Es un hecho que en México la donación de arte es una práctica cultural escasa, lo cual evidencia una falta de compromiso social de las elites con el fortalecimiento del ámbito artístico; no obstante, al revisar, aunque sea brevemente, la historia de una institución como el Museo Nacional de San Carlos, se encuentran notables casos de solidaridad cultural. Al paso de los años, dichas donaciones representan un tercio del acervo, conformado por alrededor de I 800 piezas que constituyen su patrimonio. Resulta importante destacar que las generosas cesiones, si bien aisladas y esporádicas, se iniciaron justo al mismo tiempo que se promovió la fundación de la Academia de San Carlos, en I78I.

Hace falta un análisis detallado de los donantes, tanto de la Academia como del Museo Nacional de San Carlos, aunque ya hay un perfil de los suscriptores de la Academia ${ }^{\mathrm{I}}$ del que se desprende que pertenecían a las elites — muchos de ellos eran descendientes de la nobleza virreinal que convivían con algunos prominentes empresarios o profesionistas prósperos-, composición que

I. Esther Acevedo et al., "El patrocinio de la Academia y la producción pictórica, I843-1857", en VII Coloquio Internacional de Historia del Arte. Las academias de arte, México, Universidad Nacional Autónoma de México-Instituto de Investigaciones Estéticas, I985, pp. 87-I35. 
resulta distante de la del siglo $\mathrm{xx}$, si bien configurada por algunos herederos del Porfiriato en que predominaban nuevos ricos sin tradición en el consumo de objetos suntuarios. Por tanto, en ambos siglos, un pequeño porcentaje de ellos configuró colecciones y llevó su afición estética a elevados niveles de compromiso, aunque éste no llegó al grado de entregar sus posesiones a alguna institución cultural, salvo honrosas excepciones.

Durante el siglo XIX, registrarse en la lista de suscriptores de la Academia connotaba el disfrute de una sólida posición económica y ciertas prácticas culturales; ${ }^{2}$ estar iniciado en la percepción del arte y enterado de las nuevas manifestaciones creativas indicaba la posibilidad de reclamar una posición dentro de los estratos más elevados de la sociedad. ${ }^{3} \mathrm{~A}$ lo largo del siglo xx, una vez perdido el liderazgo monopólico de aquella respetada institución y con el consiguiente surgimiento de noveles espacios culturales, la obligada participación de la nueva y vieja burguesías en alguno de estos espacios se fue diluyendo. Ya no se consideró requisito indispensable para pertenencer a la elite el financiamiento de alguna afamada institución artística; el prestigio y el reconocimiento social comenzarían a vincularse con otras prácticas y consumos, no necesariamente culturales. Por ejemplo, una disyuntiva típica a finales del siglo xx podía consistir en elegir entre formar una colección de arte contemporáneo o invertir en otro avión. ${ }^{4}$

El coleccionismo de la ciudad de Puebla, uno de los más sólidos del siglo XIX, aportó dos valiosos acervos cuyo destino, al menos en parte, fue la Academia: del abogado y político de primera línea del liberalismo, Joaquín Cardoso (I802-1878), se vendió en I88I un lote de 25 piezas; el otro fue Alejandro

2. Otro centro de reunión elitista, ya en el Porfiriato, fue el Jockey Club, fundado en i891: "La cultura del Club en su forma más atractiva y en consonancia con los hábitos mundanos, estaba representada por coleccionadores famosos de obras de arte, como Guillermo de Heredia, el arquitecto; Ramón Alcázar, rico hombre de Guanajuato, y José Aburto”. José Juan Tablada, La feria de la vida, México, Botas, 1937, p. 275.

3. Para realizar una exposición extraordinaria, en donde se esperaba atraer a diversas clases sociales, efectuada entre diciembre de 1902 y enero de 1903, la Dirección de la Escuela de Bellas Artes insistía en que se le enviaran 20 gendarmes porque "el público que concurrirá esos días no será de lo muy escogido de la sociedad”. Eduardo Báez Macías, Guía del archivo de la antigua Academia de San Carlos. 1867-1907, México, Universidad Nacional Autónoma de México-Instituto de Investigaciones Estéticas, 1993, vol. II, pp. 672-673.

4. Osvaldo Sánchez, "Mejor cómprate otro avión. Dilemas del coleccionismo de arte contemporáneo en México", en Ercilia Gómez Maqueo (coord.), Hablando en plata: el arte como inversión, México, Landucci, 2002, pp. 90-I24. 
Ruiz Olavarrieta (I82 I-I895), de quien ingresaron en 1908 cerca de 300 cuadros de maestros europeos, de los cuales algunos permanecieron en exhibición en las galerías de la escuela, al menos hasta $1916 .^{5}$

Si bien a lo largo del siglo xx las donaciones se caracterizaron por su irregularidad, conviene destacar que en su mayoría no se trata de donativos de mexicanos, sino de extranjeros. Aunque algunos de ellos eran refugiados, otros recurrieron a esa práctica como estrategia para fortalecer las relaciones político-culturales entre sus naciones de origen y México. Por ejemplo, de la colección del acaudalado empresario judío-vienés Julius Priester (I874-1955), se donaron a mediados de los años sesenta dos cuadros importantes, atribuidos a Franz Hals y a Peter Paul Rubens; otro caso fue la donación de una pintura con motivo de la Exposición de la Colección Armand Hammer (I898-1990) realizada en el Palacio de Bellas Artes en 1977.

En sentido semejante al de las donaciones, el coleccionismo de arte ha sido una práctica cultural más bien reducida, y esta aseveración es válida tanto para el siglo XIX como para el Xx. Tal carencia se explica, en parte, por la inestabilidad política y financiera que caracterizó, en especial, al periodo decimonónico, lo que en cierta medida obstaculizó la perdurabilidad de una elite socioeconómica educada e interesada en las manifestaciones artísticas del pasado y del presente. ${ }^{6}$ Durante las fases de cierta bonanza económica y de tranquilidad política que se alternaron a lo largo de los dos últimos siglos se integraron significativas colecciones de arte. Tanto durante la paz interna que se forjó con el triunfo del liberalismo como en la posrevolución, se generó cierto boom coleccionista y se crearon acervos de mayor ambición estética.

5. Báez, op. cit., pp. 849-850. Poseía no sólo pinturas sino una gran diversidad de materiales, tales como porcelanas, esmaltes, marfiles y bronces, entre otros. Hay un Inventario de las colecciones de pintura y cerámica, que legó el finado D. Alejandro Ruiz Olavarrieta [...] al Palacio Nacional de Mexico, Puebla, 1907.

6. "La nuestra es una sociedad que ha tenido constantes relevos sociales, y en consecuencia ha carecido de una aristocracia pudiente y culta, que en Europa suele ser el prototipo del mecenas y ha carecido también de una burguesía suficientemente asentada." Jorge Alberto Manrique, "El mecenazgo", en Historia del arte mexicano. Arte contemporáneo, IV, México, Secretaría de Educación Pública/Salvat, 1986, t. 16, p. 2405. 
Es sabido que, para legitimar y difundir sus posesiones, muchos coleccionistas decimonónicos buscaban afanosamente participar en las exposiciones anuales de la Academia de San Carlos. Ésta, además de ser la escuela de arte más reconocida en el territorio nacional, también constituía el espacio de exhibición más codiciado y el que mayor distinción y prestigio confería, no sólo a las piezas mostradas y a sus autores, sino, primordialmente, a sus propietarios. La coincidencia en el gusto, en lo particular y lo institucional, propicia una buena comunicación entre ambos y contribuye al fortalecimiento del liderazgo estético de la Academia. Si bien cada coleccionista asigna un orden y un sentido especial a sus acervos, el que se tratase de objetos que dicha escuela aceptaba exhibir indica cierta uniformidad en el gusto, un similar deseo estético, un esquema de valores plásticos íntimamente articulado; más aún, lo que consumían - y presumían - los particulares era análogo a lo que, de ser posible, hubiera adquirido la institución.

La diferencia entre ambas instancias — particular e institucional- estriba, principalmente, en los capitales disponibles para la inversión. En conjunto, la capacidad económica de los particulares era mucho mayor y eso es evidente sólo al cuantificar las piezas exhibidas a lo largo de ese siglo. Además, los cuadros más costosos, de los creadores más cotizados en la época, no eran por lo general los que se compraban expresamente para la Academia. En consecuencia, mantener al día a los públicos locales de lo que sucedía en el arte europeo era una importante función que recaía prioritariamente en los particulares, ya que las novedades se exhibían con especial interés poco después de su llegada al país. Si bien la actualización y la vanguardia del arte estaban en sus manos, la institución no desatendió del todo el renglón de las adquisiciones, sobre todo en el periodo en que gozaba de independencia económica y no le afectaban en absoluto las crisis políticas. De esta manera, los coleccionistas privados desempeñaban una función de complementariedad respecto a la principal corporación artística del país: educar a los iniciados tanto como a los futuros creadores era una misión compartida. José Bernardo Couto (I803-I862) destacó la importancia de formar el gusto de los nuevos ricos:

Algún día conocerán [...] que la ornamentación que hoy dan a sus casas, y en que por cierto no se muestran parcos, revela un gusto poco culto y sin doctrina: gusto de mercaderes que derraman con profusión el dinero, no de personas entendidas, que sepan sentir y juzgar. Un enorme espejo, una alfombra en que se hunde el pie como un césped de jardín, les llaman más la atención y son pagados a mejor precio que un 
excelente cuadro, un cornisamento, una perspectiva, un paisaje hechos con sabiduría. Cuando una educación más cuidada enderece y purifique sus gustos, se correrán de eso y conocerán que nunca los artefactos mecánicos pueden parangonarse con las obras del ingenio. ${ }^{7}$

Ahora bien, los coleccionistas mexicanos tenían poder adquisitivo, pero no tanto como para comprar piezas ultravaliosas de los grandes maestros; por una parte, aquí no eran tan frecuentes las grandes fortunas empresariales o las abultadas herencias — del tipo de las de Catharine Lorillard Wolfe (I828-1887), Collis Potter Huntington (I82I-I900), George Palmer Putnam (I8I4-I872) y John Pierpont Morgan (I837-1913), todos ellos importantes donadores del Museo Metropolitano de Arte fundado en Nueva York en 1872, o cualquier otro poderoso coleccionista contemporáneo de Estados Unidos, como William Henry Vanderbilt (I82I-I885), Henry Clay Frick (I849-19I9) y Charles Lang Freer (1854-1919) - necesarias para pagar importantes piezas originales de los creadores clásicos, acompañadas siempre de documentación e impresionante fortuna crítica.

Lo que seleccionaban los mexicanos lo constituían, en un alto porcentaje, piezas de taller, anónimas, creadas por artistas adscritos al círculo de algún connotado maestro, y si ocurría que se trajera una firma reconocida, pocas veces se hallaba en obras emblemáticas. Éstas escaseaban en el mercado y el precio en que se comercializaban era ya altísimo. Ante tales limitantes para conseguir creaciones libres de sospechas de falsificación, se recurría de manera sistemática a los grabados que traducían y volvían asequible el objeto inalcanzable y, ciertamente, sus réplicas. El amplio mercado surgido para los facsímiles, que pasa por el encargo directo, indica la importancia concedida a la práctica social del remplazo.

Así, dentro del plano internacional, el acopio mexicano de "grandes maestros" posee bajo perfil. No es un coleccionismo de highlights. Acervos de mayor pretensión hubieran obedecido a un interés plástico superior e implicado esfuerzos financieros extraordinarios. Fue una opción que no se ejerció ni en el siglo XIX ni en el xx, y la tendencia resultante de ello fue entonces el interés por la cantidad. Luis Castillo Ledón, historiador y funcionario cultural, criticó esta estrategia: "Toda colección es más estimada en proporción al mayor

7. José Bernardo Couto, Diálogo sobre la historia de la pintura en México, México, Consejo Nacional para la Cultura y las Artes, 1995, p. I24. 
número de ejemplares distintos e importantes que tiene y no al número de piezas que la forman". ${ }^{8}$

Numeralia y eclecticismo en realidad obedecen a que, con conjuntos tan amplios y diversos, se satisfacían diferentes demandas: el arte debía contener elementos de identidad, con lo que se incorporaban temáticas y autores nacionales o regionales, pero al mismo tiempo debía incluir valores clásicos, humanistas y universales. Sin duda, la preferencia por piezas de arte antiguas, ya fueran virreinales o europeas, indica la búsqueda del origen: "El objeto antiguo es siempre, en la acepción rigurosa del término, un 'retrato de familia". ${ }^{9}$ La incertidumbre está en el futuro; lo sólido, en el pasado. El coleccionismo "tiene la virtud de personificar el pasado en cosas tangibles". ${ }^{\text {Io }}$

En este sentido, se explica que la necesidad de vínculos con la plástica europea se haya vivido también como recurso eficaz contra la insularidad en que la flamante nación temía quedar, mirando sin ver a los otros países americanos de reciente formación. Incluso debido a esto prevalecían prácticamente sin cuestionamientos los modelos estéticos de la vieja Europa y esta relación de espejo-reflejo justificaba que un alto porcentaje de los objetos concentrados en las exposiciones fuera de procedencia extranjera y que los elaborados aquí imitaran dichos modelos iconográficos.

Al mismo tiempo, la nostalgia poscolonial, la añoranza de la estabilidad novohispana, la aristocracia perdida y la tradición trastocada lleva a las elites, en cierto porcentaje formadas por herederos de prominentes familias virreinales, a privilegiar el acopio de bienes culturales y objetos artísticos de aquel periodo. El fenómeno del nacionalismo, ligado a la construcción del nuevo Estadonación, contribuyó a que se indagara lo propio. Se comienza entonces a buscar códigos de identidad en tanto grupo social, clase privilegiada o elite política. Así, un amplio sector de los coleccionistas decimonónicos creó al menos un conjunto de arte virreinal en medio de un acervo predominantemente europeo. Esta proporción entre arte local e internacional se irá revirtiendo conforme se consolide el nacionalismo como corriente ideológica alentada desde el

8. Citado en María Hernández Ramírez, "La colección Alcázar", Diario de Campo. Revista del Instituto Nacional de Antropología e Historia, núm. 68, agosto de 2004, p. 29.

9. Jean Baudrillard, El sistema de los objetos, Francisco González Aramburu (trad.), México, Siglo XXI, I997, p. 85 .

Io. Joseph Ballart, El patrimonio histórico y arqueológico: valor y uso, Barcelona, Ariel, 2002, p. 50. 
Estado, esto es, en la medida en que vaya avanzando el siglo xx. Aquí es necesario hacer una salvedad: los coleccionistas más jacobinos fueron los únicos que decidieron no adquirir el arte del pasado, ya que la temática predominante, la religiosa, no podía obedecer a otro origen que no fuera el de la circulación de piezas provenientes de templos y conventos otrora propiedad eclesiástica.

En sentido contrario, muchas colecciones, en especial pertenecientes a lugares de talante más conservador, como Puebla, nacieron justamente para proteger, resguardar y conservar los importantes acervos religiosos que estaban en peligro real de expolio o destrucción. También allí fueron pioneros en la inclusión de núcleos interesantes de carácter regional, que reproducían formas, técnicas y temáticas provenientes de la tradición y el costumbrismo. ${ }^{\text {II }}$ Es sabido que para el coleccionismo poblano resulta fundamental la pintura de Agustín Arrieta (I803-1874), y no sólo porque se coloca obra de manufactura local en convivencia con la prestigiada tradición europea, sino también porque se documenta su región, su contexto, su otredad: "cómo viven los otros", las distintas clases sociales, "los que no son como yo pero habitan la misma región". No hay identificación con los tipos populares representados, pero sí con su contexto. Es un tête à tête ahora en el ámbito de lo interno, en la estructura de una sociedad concreta que progresivamente adquirirá mayor importancia hasta su fase culminante: el coleccionismo nacionalista de mediados del siglo Xx. Otro caso paradigmático, equiparable en importancia al de Arrieta, es el de José María Velasco (I840-I9I2), ya que acumular su obra se convirtió para los coleccionistas mexiquenses - con el político y empresario Carlos Hank González como guía - no sólo en la documentación visual de su patria chica sino en la representación del centralismo político y económico del régimen autodenominado posrevolucionario: el altiplano central como el ombligo, la cuna de la nación mexicana... añeja construcción ideológica.

El coleccionismo ha sido una de las más importantes fuentes constitutivas del patrimonio cultural. Una trascendente colección de arte marca a su contex-

I I. Véase Fausto Ramírez, "El arte del siglo xix", en Historia del arte mexicano, México, Secretaría de Educación Pública-Salvat, I986, t. 9, p. I224. Estoy en deuda con el maestro Ramírez por sus sugerencias bibliográficas y recomendaciones al elaborar este y otros textos. 
to, no sólo en tanto conjunto de objetos de enorme valía simbólica o en tanto canon del buen gusto, sino sobre todo como un ensayo de construcción identitaria que influye en el imaginario social.

A pesar de que la historia del coleccionismo decimonónico en México es tarea pendiente, resulta indispensable al menos mencionar a personalidades señeras que, encabezadas por Rafael Lucio, gozaron de distinción y prestigio en su época: Ignacio Pérez de Salazar y Venegas, Francisco Fagoaga, Eustaquio Barrón, Octaviano Muñoz Ledo, Carlos Sánchez Navarro y Berain, Anselmo Zurutuza, Manuel Diez de Bonilla, Juan José Baz, José Pablo Martínez del Río, Joaquín Cardoso, Joaquín Flores, José Vázquez Tagle, José María Baz, Julio Michaud, Ramón Alcázar, ${ }^{\mathrm{I2}}$ Guillermo Heredia, ${ }^{\mathrm{I} 3}$ José Aburto y los Escandón: Vicente, Manuel y Antonio, además de Alejandro Arango y Escandón, entre otros. En este breve listado no pueden faltar ni el poblano José Luis Bello y González, en su calidad de fundador de una célebre dinastía coleccionística, ni José Manuel Gargollo y Garay, heredero de una reconocida familia de opu-

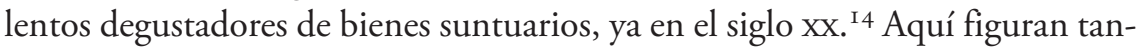
to liberales como conservadores, políticos como empresarios, editores como escritores. Y la única mujer registrada como coleccionista, María Pardo, dio a conocer seis imágenes religiosas, probablemente sólo una fracción de su acervo, en 1902. ${ }^{15}$ Cabe destacar que todo coleccionista participa de la atmósfera cultural de su tiempo y que sus ideas y selecciones guardan una estrecha relación con las prácticas culturales contemporáneas a él.

I2. "Alcázar fue también benemérito adquiriendo para su colección obras de arte únicas, que sin su intervención habrían, como tantas otras, emigrado al extranjero." Tablada, op. cit., p. 277. Es probable que el conjunto de pintura de la colección de Ramón Alcázar (I843-19I6) no haya sido de primer orden, ya que, aunque el guanajuatense llegó a poseer alrededor de 30000 objetos como joyería, muebles y artes aplicadas, entre otros, cuando en I9I7 una pequeña parte de la colección, con poco más de 7000 piezas, aunque no de las más valiosas, llegó al Museo Nacional, alrededor de 200 eran pinturas y fueron clasificadas por su director Castillo Ledón como de baja calidad, salvo unas cuantas excepciones, entre ellas un aguafuerte atribuido a Rembrandt. Citado en Hernández Ramírez, op. cit., pp. 27-29.

I3. "Nunca admiré colección mexicana integrada con mayor buen gusto, ni conocí coleccionador que tan bien aquilatara y explicara a sus amigos el mérito de cuanto poseía." Tablada, op. cit., p. 276.

I4. Véanse dos libros de Miguel Ángel Fernández: Historia de los museos de México, México, Promotora de Comercialización Directa, I988, y Coleccionismo en México, Monterrey, Museo del Vidrio, 2000.

I5. Báez, op. cit., p. 680. 
Dentro de este grupo, es posible distinguir al menos dos arquetipos: la minoría ofrendó un buen porcentaje de su vida y su capital al consumo estético e incluso algunos practicaron la crítica de arte, promovieron y gestionaron colecciones y hasta restauraron obras, como lo hicieron Rafael Lucio y Alberto J. Pani. ${ }^{16} \mathrm{El}$ modelo más común fue el de quienes, si bien cultivaban gustosamente su pasión por el arte y consumían más objetos de los que necesitaban para decorar sus espacios de representación, privados o públicos, su dedicación no fue ilimitada o no se interesaron por participar en la difusión del arte que acumulaban, e incluso la mayoría decidió no donar ni vender al Estado, con lo que no perpetuaron su nombre en el ámbito cultural ni lo ligaron indefectiblemente con sus posesiones.

Todos ellos acumularon conjuntos diversos de arte capaces de presentar una visión panorámica con acento en expresiones del pasado y con abundancia de piezas estrictamente decorativas. Si bien algunos realizaron una selección cuidadosa, al menos a simple vista no son perceptibles las estructuras de sus colecciones. Al parecer la depuración no se realizaba de manera sistemática y no se priorizaba su singularidad. Es por ello que, en sentido estricto, estos personajes no formaron colecciones modelo en su tiempo ni para los coleccionistas contemporáneos ni para los otros iniciados en el ámbito artístico mexicano. Cabe recordar que la mayor parte de estas selecciones correspondía a corrientes o autores reconocidos y hasta consagrados, por lo que no se corría el riesgo de perder la inversión y, en cambio, tal renombre volvía ésta mucho más segura y rentable, pues por regla general el prestigio de una pieza se transmite simbólicamente a su poseedor.

El arquitecto Manuel Francisco Álvarez, en un texto publicado en 1904, jerarquiza así a los coleccionistas más encumbrados:

El señor Fagoaga a principios del siglo xIx fue el primero que dedicando fuertes sumas de su caudal compró muchos cuadros [...] El Dr. D. Rafael Lucio, de un claro talento y de gusto por el arte, pudo formar una rica colección [...] El lic. D. Joaquín Cardoso formó su colección por compras aisladas de cuadros de varios comerciantes en pinturas; y a su muerte fueron vendidos veinte y tantos cuadros [...] El Lic. D.

I6. Véase un bosquejo de su perfil como coleccionista y agente cultural en mi artículo "Adjudicar y donar: forjando la heredad pictórica del Mnsc", en Museo Nacional de San Carlos. Memoria. 1968-2008, México, Instituto Nacional de Bellas Artes/Museo Nacional de San Carlos, 2008, pp. 73-88. 
Felipe Sánchez Solís, además de haber reunido pinturas de mérito, protegió a los artistas [...] D. Eustaquio Barrón llegó a reunir una colección de más de 200 cuadros de los mejores autores y muchos originales [...] de Van Dyck [...] de Ribera [...] de Holbein [...] de Lucas Jordán [...] de Zurbarán [...] de Alonso Cano. ${ }^{17}$

Cabe destacar que ya en I843 Francisco Fagoaga (I788-185 I) formaba parte de una generación de reconocidos coleccionistas. ${ }^{18}$ Álvarez, que estudió sus conjuntos y subconjuntos, algunos de ellos institucionalizados y otros en continua circulación, escribió respecto a él lo siguiente:

Comisionó al inteligente Madrazo para que adquiriera pinturas en Espańa y en otras naciones [...] así es como se explica que haya habido en México pinturas de notables artistas, las que muchas de ellas han vuelto a Europa. La colección [...] [tenía] más de 200 cuadros [...] en copias manuscritas ha andado en manos de los amateurs, para ver cómo se hacen de aquellas pinturas [...] hubo originales de Zurbarán, Alonso Cano, Rubens, Vankelmont, Bosch, Velázquez; la Familia real de España de Vankessel [...] de Zurbarán el Bautismo de Santo Domingo, El milagro de los misales y la Adoración de los pastores. De Peternoffs Perspectiva de catedral flamenca y otra de un templo de Vuroni, que tal vez fueron las que después poseyó el Dr. Lucio y salieron del país. Tres vacas de Pedro Pablo Potter; un Ecce-Homo del Divino Morales, etcétera. De muchos de estos cuadros se enriqueció la colección Abadiano ${ }^{19}$ y otras varias. ${ }^{20}$

17. Manuel Francisco Álvarez, Las pinturas de la Academia Nacional de Bellas Artes. Su mérito artístico y su valor comercial, en Memorias de la Asociación de Arquitectos e Ingenieros de México, México, Asociación de Arquitectos e Ingenieros, 19I 4, pp. 29I-294. Para conocer las procedencias del acervo del Museo Nacional de San Carlos, véase Áurea Ruiz, "Introducción”, en Catálogo comentado del acervo del Museo Nacional de Arte. Siglo XIX, México, Munal, 2004, t. I. Alfonso Sánchez Arreche realizó un estudio del perfil del coleccionista y político mexiquense: "Los motivos de un mecenas: Felipe Sánchez Solís”, en Gustavo Curiel (comp.), XX Coloquio Internacional de Historia del Arte. Patrocinio, colección y circulación de las artes, México, Universidad Nacional Autónoma de México-Instituto de Investigaciones Estéticas, 1997, pp. 77-94.

I8. L.E., "Bellas Artes", en El museo mexicano, México, Ignacio Cumplido, I843, t. I, p. 267. Citado en Ida Rodríguez Prampolini, La crítica de arte en México en el siglo XIX, México, Universidad Nacional Autónoma de México-Instituto de Investigaciones Estéticas, I997, vol. I, pp. I78-I79.

19. Francisco Abadiano, coleccionista y librero. En I859 tenía una imprenta en Escalerillas I3 y en I87 I escribía para el semanario de la Sociedad Católica de Seńoras. Couto señala en su Diálogo que era bisnieto del pintor Cabrera. Fue suscriptor de la Academia y exhibió i 8 piezas de su propiedad en dos exposiciones, de 1852 y 1869.

20. Véase Álvarez, op. cit., pp. 29I-292. 
A pesar del carácter utópico de la mayoría de las atribuciones autorales aquí consignadas, estoy convencida de que la Colección Fagoaga representó un parteaguas en el coleccionismo nacional porque influyó en el imaginario colectivo por mucho tiempo después de muerto el compilador y su eclecticismo fue un modelo a seguir en las siguientes décadas. Además, en tanto funcionario público de los primeros años de la vida independiente, Fagoaga inauguró la tradición del político-coleccionista que mantendrá vigencia hasta finales del siglo $\mathrm{xx}^{2{ }^{21}} \mathrm{En}$ buena medida, su éxito y su visibilidad pública se debieron a que elegía en el círculo de lo legitimado-consagrado y se aseguraba de obtener los más representativos bienes simbólicos a su alcance, vía un reconocido creador habilitado como buscador de tesoros: el español Madrazo, ubicado no en la periferia, sino en el centro mismo de la canonizada producción plástica. ${ }^{22}$

Su contemporáneo fue un coleccionista de origen extranjero aunque avecindado en México, quien se distinguió por ser uno de los primeros heterodoxos que incluyeron en sus selecciones piezas del otrora desfavorecido arte virreinal; el cambio en los marcos de legitimidad operado desde la gestión de José Bernardo Couto en favor de lo novohispano es perceptible en la morfología de las colecciones.

Eustaquio Barrón llegó a reunir una colección de más de 200 cuadros de los mejores autores y muchos originales [...] de Van Dyck Antonio (I599-I64I) El calvario; de Ribera San Benito Abad; de Juan de Juanes El cenáculo, tabla; de Holbein Juan (I495-I554) un retrato en tabla y otro cuadro de Santa Isabel; de Lucas Jordán San Miguel; de Zurbarán El rey David; de Alonso Cano San Agustín; de Francisco Snyders (I579-I637) una Cacería; de Ibarra una Purísima y una Virgen del Rosario; de Rigaud dos cuadros; de J. Artor una Aldeana; de Echave una Sagrada familia y otros cuadros que aunque copias tienen bastante mérito. ${ }^{23}$

Lo más probable es que se trate de la colección de uno de los hombres más ricos de Nayarit en la primera mitad del siglo XIX, quien, a través de sus diversos ne-

2I. Político nacido en la ciudad de México. Asistió en calidad de diputado a las Cortes de Cádiz y fue senador en varias ocasiones. En I824, fue nombrado presidente municipal de México. Por breve tiempo, en I832, fungió como ministro de Relaciones Interiores y Exteriores. Entre sus actividades relacionadas con el arte se sabe que fundó una academia de dibujo y contribuyó al fomento de la Escuela de Artes y Oficios.

22. José Madrazo y Agudo (I78I-I859), pintor de cámara de Carlos IV.

23. Álvarez, op. cit., p. 294. 
gocios, ejerció un poder económico casi monopólico en Tepic y luego extendió su influencia a todo el territorio nacional. ${ }^{24}$ Radicó en la ciudad de México después de I 848 , fecha en que regresó de un viaje de dos años por diversos países del orbe. ${ }^{25}$ Como siempre, las pretensiones de contar con objetos originales sacralizados hizo que en los listados se incorporaran, con cierto grado de verosimilitud o no, los grandes nombres del arte internacional.

En la segunda mitad del siglo XIX, el líder indiscutible del coleccionismo de pintura de caballete es el médico Rafael Lucio y Nájera (I8I9-1886), ${ }^{26}$ quien mostró cerca de 200 piezas en siete exposiciones de la Academia realizadas entre I 869 y I $886 .{ }^{27}$ Se trata de un caso paradigmático: poseía tanto arte virreinal como europeo, laico y religioso, en todos los géneros y variadas técnicas, pero a simple vista, revisando los enormes listados de sus posesiones, no pareciera tratarse de un caso de acumulador estricto, que definiera una estructura visible

24. Eustaquio Barrón incursionó con éxito en la banca, el comercio y la industria y poseyó también importantes haciendas, además de un ingenio azucarero. Su principal instrumento de poder económico fue la Compañía Barrón and Forbes, fundada alrededor de 1827 y con vida hasta I885, año en que la empresa se disolvió. Barrón fue cónsul de Gran Bretaña y William Forbes de los Estados Unidos, y ambos se alinearon a los conservadores en materia de política.

25. El escultor italiano Antonio Piatti realizó el busto en mármol de Barrón, que se exhibió en la exposición de la Academia correspondiente a I 862. Para la tumba del coleccionista, el mismo creador representó a Cristo también en mármol. "Exposiciones de la Academia Nacional de San Carlos. I862", El Siglo XIX, I7 de febrero de I862, p. I, y "La estatua del Salvador”, El Siglo XIX, I4 de enero de I863, p. 4. Citados en Rodríguez Prampolini, op. cit., pp. 39 y 91. La familia Barrón se relacionó vía enlaces matrimoniales con otro poderoso clan de la época, los Escandón, y las excentricidades de uno de sus descendientes del mismo nombre, un provocador y supuesto antidandy del Porfiriato, fueron registradas gozosamente por José Juan Tablada y Salvador Novo.

26. Su estatua, realizada por el gobierno de Veracruz, su estado natal, fue develada en el Paseo de la Reforma tres años después de su muerte. Escribió una breve Reseña histórica de la pintura mexicana en los siglos XVII y XVIII. Es posible que haya sido uno de sus herederos, Alberto Lucio, quien decidió donar a la Escuela Nacional de Bellas Artes dos pinturas religiosas europeas en 1906. Báez, op. cit., pp. 874 y 88I.

27. El promedio era mucho menor; por ejemplo: Octaviano Muñoz Ledo inscribió is piezas en tres exposiciones, Manuel Diez de Bonilla presentó i I en dos eventos, Francisco Abadiano I8 trabajos también en dos certámenes; en el grupo de coleccionistas-artistas, Lorenzo de la Hidalga participó en tres exhibiciones con un total de diez objetos y Eugenio Landesio en igual número de muestras desplegó quince creaciones. Nótese que el liderazgo de Lucio resulta de que ningún otro coleccionista presentó cantidad similar de objetos en las exposiciones que registró Romero de Terreros; hace falta un estudio detallado para delinear con precisión su perfil. Véase Manuel Romero de Terreros, Catálogos de las exposiciones de la Antigua Academia de San Carlos de México (I850-I898), México, Imprenta Universitaria, I963. 
para sus selecciones, y más bien da la impresión de que su eclecticismo refleja el mismo horror vacui que viven muchos otros coleccionistas, contemporáneos y posteriores. Todo indica que el acento social y por tanto el prestigio conseguido al exhibir en la Academia era directamente proporcional a la cantidad de lo "remitido". ${ }^{28} \mathrm{Y}$, en este rubro, sin duda, Lucio no tenía competidor cercano, al menos entre los miembros de su generación.

Ahora bien, sólo un sector de la elite de los coleccionistas tenía interés en exhibir al menos una parte de sus posesiones en la Academia, llamada a partir de 1867 Escuela Nacional de Bellas Artes. No obstante, muchos otros contaban también con visibilidad social y prestigio aunque se mantenían al margen de la institución, tal como ocurría con algunos coleccionistas de obras de José María Velasco: Francisco Kaska, Manuel Ibarrola y Leopoldo Weber. En cambio, otros eran asiduos participantes de ella: Manuel Payno, Felipe Sánchez Solís, Rafael Ortiz de la Huerta y Manuel Sánchez Facio. Estos casos confirman que un estudio detallado del coleccionismo decimonónico no puede limitarse a revisar sólo las exposiciones de la Academia.

Como es sabido, en el siglo xx persiste y culmina la búsqueda de identidad, aunque mediante nuevos parámetros estéticos. Por ejemplo, en 1903, el director del Museo Nacional exhorta a los alumnos de la Escuela de Bellas Artes a ir a dibujar al salón de monolitos, rebosante de esculturas mesoamericanas, ya que "así podría irse formando poco a poco un gusto característico, que más tarde podría servir para formar un estilo nacional”. ${ }^{29}$ La pretensión del régimen posrevolucionario, secundando los postulados liberales enunciados desde décadas anteriores, fue la de dotar a nuestro país de un rostro diferente, uno que le proporcionara distinción en el concierto de las naciones y, sobre todo, que lo colocara en condiciones de igualdad cultural. Así, el hincapié se hizo en el despliegue prioritario de las diferencias estéticas, en tanto éstas se postularon como herederas de una tradición plástica de antigua raigambre — y allí entraba

28. En la categoría de "remitidos", se registraron durante muchos años en los catálogos que editaba la Academia los cuadros de propiedad privada que no provenían de las industriosas manos de sus alumnos.

29. Báez, op. cit., p. 706. 
el arte mesoamericano que, si bien exótico, documentaba la ancestral civilidad de nuestra cultura-, cuya culminación era el movimiento artístico surgido en las primeras décadas del siglo pasado. El muralismo y su transcripción al pequeño formato, de modernidad indiscutible, con temáticas universales por las que siempre pugnó Orozco, con lazos sutiles con las vanguardias europeas visibles en la obra de Rivera y Siqueiros, permitieron al arte propio alcanzar condiciones de igualdad respecto al internacional.

Dentro de este panorama más contestatario y de acentuado nacionalismo, el arte virreinal, el decimonónico y el occidental antiguo — salvo excepcionesperdieron visibilidad e interés dentro de la jerarquización establecida por las políticas culturales estatales. Es por ello que estos tipos de acervos públicos quedaron marginados dentro del sistema de museos que se fue configurando a lo largo del siglo pasado, no sin trastabilleos o reformulaciones. Y aunque todavía a mediados de los ańos cuarenta de esa centuria predominó el arte antiguo europeo en las colecciones más representativas, estos conjuntos prácticamente no llegaron a las colecciones del Estado. Un ejemplo significativo es el de Licio Lagos (1902-1992), quien adquirió obras de Velázquez, Zurbarán, Zuloaga, Mariano Fortuny, Moritz Rugendas, Federico Waldeck, Jean Baptiste Louis, Pharamond Blanchard, Daniel Thomas Egerton, Conrad Wise Chapman, Eugenio Landesio, José María Velasco, Joaquín Clausell y Germán Gedovius, además de un conjunto de arte novohispano y otro de pintores adscritos a la corriente hegemónica de las primeras décadas del siglo xx. Tan ecléctico acervo fue seccionado y una porción importante se vendió a una de las más poderosas instituciones culturales en el ámbito privado: Fomento Cultural Banamex.

Sin duda el coleccionismo mexicano, como fenómeno social, se ha caracterizado hasta ahora por una reducida tendencia a la donación de obras aisladas o conjuntos de arte y por una escasa vocación por fundar nuevas instituciones artísticas. Es por ello que, en su gran mayoría, tales posesiones se mantienen en circuitos particulares. Y aquí es necesario destacar, entonces, la trascendencia de fundaciones como las de Franz Mayer, Antonio Haghenbeck y la familia Slim, quienes en las últimas décadas crearon espacios para garantizar la exhibición permanente de sus acervos; los museos Franz Mayer, Casa de la Bola y Soumaya no sólo enriquecen nuestro panorama cultural, sino complementan los discursos artísticos del Museo Nacional de San Carlos. \$े 